\title{
Comparison of the damaging effects of Meloidogyne incognita on a resistant and susceptible cultivar of cucumber
}

\author{
Tariq Mukhtar ${ }^{1, \star}$ iD , Muhammad Zameer Kayani² (D) \\ 1.Pir Mehr Ali Shah Arid Agriculture University - Department of Plant Pathology - Rawalpindi (Punjab), Pakistan \\ 2.Department of Agriculture - Tehsil Kahuta - Rawalpindi (Punjab), Pakistan
}

\begin{abstract}
In the present study, the damaging effects of six inoculum densities of Meloidogyne incognita were compared on a resistant (Long Green) and a highly susceptible (Mirage) cultivar of cucumber. All the inoculum densities of $M$. incognita resulted in significant reductions in growth and yield variables of both the cultivars over their controls. The reductions in resistant cultivar were significantly lower as compared to the highly susceptible cultivar at all inoculum levels. The highest inoculum level caused the maximum reductions in growth and yield variables while the lowest inoculum level resulted in the minimum reductions. The reductions in growth and yield variables increased with an increase in the inoculum density showing a positive relationship. On the other hand, the inoculum levels caused an increase in root weight. The higher inoculum levels caused higher increases while at lower inoculum levels, the increases were lower. The increases in root weights were significantly lower in the resistant cultivar when compared to the highly susceptible one showing a direct relationship between the increase in root weight and inoculum levels. Similarly, significant differences in number of galls and egg masses were noticed between the resistant and highly susceptible cultivar at all inoculum levels. The galls produced on highly susceptible cultivar were significantly higher as compared to the resistant one. A direct relationship was observed between inoculum levels and number of galls and egg masses. On the other hand, all the inoculum levels varied significantly regarding reproductive factor on the resistant and highly susceptible cultivars.
\end{abstract}

Key words: root-knot nematode, inoculum level, reproductive factor, resistant and susceptible cultivars, damaging effects.
Received:

Sept. 11, 2019

Accepted:

Nov. 28, 2019

Section Editor:

Gabriel Constantino Blain

${ }^{\star}$ Correspondence author: drtmukhtar@uaar.edu.pk

\section{INTRODUCTION}

Like fungal, bacterial and viral pathogens, nematodes also have a qualitative and quantitative impact on crops and resultantly have profound deleterious effects on food security, particularly in poverty-stricken regions of the world. Plant parasitic nematodes have been reported to cause estimated crop yield losses of $14.6 \%$ in tropical and subtropical countries while losses of $8.8 \%$ have been observed in developed countries (Sasser and Freckman 1987). A 10\% of yield loss is incurred by these nematodes globally, which total $\$ 173$ billion annually (Elling 2013).

Similar to all other crops and vegetables, cucumber is also vulnerable to many biotic and abiotic perturbations that cause reductions in yield. Biotic factors include insect pests (Kassi et al. 2019 a, b; Aslam et al. 2019 a) and disease inciting agents (Aslam et al. 2019 b; Hussain and Mukhtar 2019; Saeed et al. 2019; Iqbal and Mukhtar 2020). Among nematodes, root-knot nematodes of the genus Meloidogyne are the most widespread and economically important (Khan et al. 2019; Mukhtar and Hussain 2019; Asghar et al. 2020; Azeem et al. 2020). These nematodes complete their life cycles in a 
relatively short period of about 25 days at a temperature of $27^{\circ} \mathrm{C}$. The comparatively short life cycle facilitates root-knot nematodes to prosper effectively when a suitable host is present and cause their populations to pullulate to the maximum as crops reach maturity. Root-knot nematodes invade an array of important crops and have been found more damaging to vegetables especially in the tropical and subtropical countries of the world (Tariq-Khan et al. 2017). So far more than 100 species of Meloidogyne have been described throughout the world and, among these, four species viz. Meloidogyne incognita, $M$. javanica, M. arenaria and $M$. hapla are commonly found. More than 3000 plant species, almost all cultivated plants, have been recorded as the hosts of root-knot nematodes. The infested plants manifest symptoms of chlorosis, stunting and unthrifty growth (Archana and Saxena 2012). Root-knot nematodes are reported to cause annual losses in the tropics up to $33 \%$ in cucumber (Sasser 1979). Among root-knot nematodes, M. incognita and M. javanica are of economic importance and the most devastating ones. Of all the root-knot species associated with cucumber, $M$. incognita constituted $79 \%$ and M. javanica 19\% in Pakistan. As a single population, M. incognita was recorded in 30\% of cucumber plantations and, as mixed population, it was predominantly found with M. javanica in 70\% of cucumber fields (Kayani et al. 2013).

Crops losses in Pakistan due to nematodes have been found more serious and complex as compared to the developed countries owing to numerous causes. Firstly, the country is positioned in the tropical region where the environmental conditions are encouraging for infectivity, growth and reproduction of these nematodes all the year round. Secondly, the arid zone of the country being sandy in nature is favorable for the activities of these nematodes. Lastly, the cultivation of perennial or susceptible crops year after year in the same piece of land in irrigated plains permits rapid multiplication of nematodes which results in severe infections and damage. On the other hand, entomopathogenic fungi and nematodes can reduce the incidence and severity of root-knot nematodes (Javed et al. 2019 a, b; Rahoo et al. 2019 a, b). Root-knot nematodes have also been found associated with fungal and bacterial pathogens resulting in disease complexes and aggravate the severity of the latter (Mukhtar and Kayani 2019; Nazir et al. 2019).

Nematode damage to plants is often measured by establishing relationships between preplant or initial nematode numbers and growth and yield of plants. The minimum nematode density that can inflict a considerable reduction in growth and/or yield of plants depends on the kind of host, nematode species, cultivars and environmental factors (Barker and Olthof 1976). Infections caused by low numbers of root-knot nematodes on poor or good hosts may not affect the plants (Madamba et al. 1965) or can result in enhancement of growth and yield of plants (Madamba et al. 1965; Olthof and Potter 1972) or can damage crops severely (Barker and Olthof 1976). The influence of inoculum levels of Meloidogyne spp. have been assessed on the extent of damage of various crops and on plants of different ages (Kayani et al. 2018), but such effects of nematode densities have not been compared between resistant and susceptible cultivars of the same plant. Therefore, the present study was designed to compare the effects of six inoculum densities of M. incognita on resistant and susceptible cultivars of cucumber.

\section{MATERIALS AND METHODS}

\section{The nematode}

An indigenous population of root-knot nematode (Meloidogyne incognita) initially isolated from cucumber roots, identified on the basis of perineal pattern and maintained on the highly susceptible cultivar of tomato (Money Maker) was used in the assessment. The nematode was mass produced on the highly susceptible cultivar of tomato (Money Maker) as previously described (Mukhtar and Hussain 2019). Second stage juveniles (J2s) were extracted from the infected roots for inoculation of plants as described by Whitehead and Hemming (1965).

\section{Damaging effects of $M$. incognita inoculum levels on resistant and susceptible cultivars}

The damaging effects of inoculum levels of $M$. incognita were assessed on a resistant cultivar of cucumber viz. Long Green and a highly susceptible one viz. Mirage (Mukhtar et al. 2013). The seeds of these two cultivars were separately sown 
in pots containing formalin sterilized soil. After germination, one healthy seedling was maintained in each pot. Ten days after emergence, each plant in the pots was inoculated with freshly hatched J2s of $M$. incognita at the rates of 250, 500, 1000, 2000, 4000 and 8000 by making four holes around the stem. The plants which were not inoculated with nematodes served as controls. There were five replications for each inoculum level. The pots were placed in a completely randomized design on a greenhouse bench at $25 \pm 2{ }^{\circ} \mathrm{C}$. The plants were watered when required.

\section{Recording of data}

Eight weeks after inoculation, the plants of both cultivars inoculated with different quantity of nematodes were gently uprooted from their respective pots and the data were recorded regarding shoot and root lengths and weights, fruit yield, number of galls, egg masses and reproductive factor. Root and shoot lengths were measured with the help of a meter scale. Fruits were harvested twice a week from the $30^{\text {th }}$ day after inoculation till the termination of the experiment. At each harvest, the total number of fruits and their weights were recorded and the total fruit yield was calculated. Data regarding numbers of galls and egg masses on the roots of each plant were taken with the aid of a stereomicroscope at a magnification of 35x. Eggs were extracted from the roots of each plant after recording egg masses as described by Hussey and Barker (1973) and their numbers were counted. Similarly, juveniles from the soil of each pot were also extracted by employing the method devised by Whitehead and Hemming (1965). The eggs extracted from the roots and juveniles from the soil were added up and the reproductive factor was calculated (Khan et al. 2019).

\section{Statistical analysis}

The test was repeated once. Before statistical analysis, percent of decreases in growth and yield components were determined over their controls. First, the data of both experiments were separately analyzed by two-way analysis of variance (ANOVA) using GenStat package 2009, (12th edition) version 12.1.0.3278, for significant interaction. As there was no significant interaction between the two experiments, the two sets of data were combined and again statistically analyzed. The means of each parameter were compared for significant differences by Fisher's protected least significant difference test at $(\mathrm{p} \leq 0.05)$. Taking nematode levels as dependent variables $(\mathrm{X})$ and reductions or increases in plant growth parameters, yield components and nematode infections as dependent variables (Y), linear relationships were established in Microsoft Excel 2010 to represent best-fit straight lines.

\section{RESULTS}

\section{Damaging effects of $M$. incognita on growth variables of resistant and susceptible cucumber cultivars}

The analysis of variance showed highly significant results regarding effects of inoculum densities on growth and yield parameters and nematode infestations. All the inoculum densities of M. incognita resulted in significant reductions in growth variables of both cultivars over their controls. The reductions in the resistant cultivar were significantly lower as compared to the highly susceptible cultivar at all inoculum levels. The highest inoculum level of $8000 \mathrm{~J} 2 \mathrm{~s}$ caused the maximum reductions in shoot and root lengths and shoot weight followed by levels of 4000 and 2000 J2s. Similarly, the lowest inoculum level of $250 \mathrm{~J} 2 \mathrm{~s}$ resulted in the minimum reductions followed by 500 and $1000 \mathrm{~J} 2 \mathrm{~s}$ as shown in Tables 1, 2 and 3. It was observed that the reductions in these growth variables increased with an increase in the inoculum density showing a positive direct relationship and these relationships have been shown by regression equations in Table 4 . On the other hand, the inoculum levels caused an increase in root weight. The higher inoculum levels caused higher increases while at lower inoculum levels, the increases were lower. The increases in root weights were significantly lower in the moderately resistant cultivar as compared to the highly susceptible one (Table 5). A direct relationship was found between the increase in root weight and inoculum levels and has been shown by regression equation given in Table 4 . 
Table 1. Effect of inoculum levels of Meloidogyne incognita on \% decrease in shoot length of resistant and highly susceptible cucumber cultivars.

\begin{tabular}{ccc}
\hline \multirow{2}{*}{ Inoculum level } & \multicolumn{2}{c}{ Cultivar } \\
\cline { 2 - 3 } & Mirage & Long Green \\
\hline 250 & $2.1 \pm 0.26$ & $0.5 \pm 0.11$ \\
\hline 500 & $6.2 \pm 0.58$ & $0.7 \pm 0.22$ \\
\hline 1000 & $8.1 \pm 1.02$ & $1.3 \pm 0.43$ \\
\hline 2000 & $14.0 \pm 1.13$ & $3.9 \pm 0.85$ \\
\hline 4000 & $17.4 \pm 1.35$ & $5.6 \pm 0.72$ \\
\hline 8000 & $23.2 \pm 1.65$ & $7.4 \pm 0.94$ \\
\hline
\end{tabular}

Data are means of ten replicates.

Table 2. Effect of inoculum levels of Meloidogyne incognita on \% decrease in root length of resistant and highly susceptible cucumber cultivars.

\begin{tabular}{ccc}
\hline \multirow{2}{*}{ Inoculum level } & \multicolumn{2}{c}{ Cultivar } \\
\cline { 2 - 3 } & Mirage & Long Green \\
\hline 250 & $2.6 \pm 0.33$ & $0.2 \pm 0.08$ \\
\hline 500 & $3.8 \pm 0.68$ & $1.3 \pm 0.32$ \\
\hline 1000 & $7.9 \pm 0.76$ & $3.0 \pm 0.54$ \\
\hline 2000 & $9.9 \pm 1.01$ & $4.3 \pm 0.68$ \\
\hline 4000 & $16.0 \pm 1.33$ & $4.9 \pm 0.87$ \\
\hline 8000 & $17.2 \pm 1.65$ & $5.4 \pm 0.68$ \\
\hline
\end{tabular}

Data are means of ten replicates.

Table 3. Effect of inoculum levels of Meloidogyne incognita on \% decrease in shoot weight of resistant and highly susceptible cucumber cultivars.

\begin{tabular}{ccc}
\hline \multirow{2}{*}{ Inoculum level } & \multicolumn{2}{c}{ Cultivar } \\
\cline { 2 - 3 } & Mirage & Long Green \\
\hline 250 & $3 \pm 0.41$ & $0.4 \pm 0.29$ \\
\hline 500 & $5 \pm 0.97$ & $0.9 \pm 0.37$ \\
\hline 1000 & $10 \pm 1.29$ & $1.3 \pm 0.73$ \\
\hline 2000 & $12 \pm 1.30$ & $4.5 \pm 0.85$ \\
\hline 4000 & $23 \pm 1.51$ & $6.3 \pm 0.92$ \\
\hline 8000 & $27 \pm 2.10$ & $7.2 \pm 1.10$ \\
\hline
\end{tabular}

Data are means of ten replicates.

Table 4. Regression equations of different growth and yield variables of resistant and highly susceptible cucumber cultivars.

\begin{tabular}{|c|c|c|c|c|}
\hline \multirow{3}{*}{$\begin{array}{c}\text { Growth and yield } \\
\text { variables }\end{array}$} & \multicolumn{4}{|c|}{ Cultivar } \\
\hline & \multicolumn{2}{|c|}{ Mirage } & \multicolumn{2}{|c|}{ Long Green } \\
\hline & Regression equation & $\mathrm{R}^{2}$ & Regression equation & $\mathrm{R}^{2}$ \\
\hline Shoot length & $y=4.1 x-2.6667$ & 0.9825 & $y=1.48 x-1.9467$ & 0.9342 \\
\hline Root length & $y=3.1886 x-1.5933$ & 0.9652 & $y=1.0886 x-0.6267$ & 0.9606 \\
\hline Shoot weight & $y=5.0286 x-4.2667$ & 0.9429 & $y=1.5257 x-1.9067$ & 0.9319 \\
\hline Root weight & $y=4.0571 x-3.8667$ & 0.9252 & $y=1.5314 x-2.06$ & 0.9396 \\
\hline Number of fruits & $y=5.1257 x-4.2067$ & 0.9309 & $y=1.3743 x-1.86$ & 0.9439 \\
\hline Fruit weight & $y=5.34 x-5.44$ & 0.9513 & $y=1.4114 x-1.9733$ & 0.8525 \\
\hline Fruit yield & $y=7.0257 x-8.0067$ & 0.886 & $y=2.1943 x-2.5467$ & 0.9661 \\
\hline
\end{tabular}


Table 5. Effect of inoculum levels of Meloidogyne incognita on \% increase in root weight of resistant and highly susceptible cucumber cultivars.

\begin{tabular}{ccc}
\hline \multirow{2}{*}{ Inoculum level } & \multicolumn{2}{c}{ Cultivar } \\
\cline { 2 - 3 } & Mirage & Long Green \\
\hline 250 & $2 \pm 0.24$ & $0.2 \pm 0.09$ \\
\hline 500 & $4 \pm 0.77$ & $0.6 \pm 0.21$ \\
\hline 1000 & $7 \pm 1.02$ & $1.4 \pm 0.47$ \\
\hline 2000 & $9 \pm 1.13$ & $4.4 \pm 0.85$ \\
\hline 4000 & $19 \pm 1.95$ & $6.3 \pm 0.92$ \\
\hline 8000 & $21 \pm 1.81$ & $6.9 \pm 1.00$ \\
\hline
\end{tabular}

Data are means of ten replicates.

\section{Damaging effects of $M$. incognita on yield variables of resistant and susceptible cucumber cultivars}

Significant variations in yield components of both resistant and susceptible cultivars were observed as a result of nematode infection; the lowest inoculum levels resulted in the minimum decreases. In the highly susceptible cultivar, the reductions in yield variables were the maximum whereas the reductions in the resistant cultivar were found to be the minimum at all inoculum levels as shown in Tables 6,7 and 8. It was also observed that the increases in these parameters occurred with the increase in inoculum levels and a direct relationship was found between inoculum levels and yield variables, as shown in Table 4.

Table 6. Effect of inoculum levels of Meloidogyne incognita on \% decrease in number of fruits on resistant and highly susceptible cucumber cultivars.

\begin{tabular}{ccc}
\hline \multirow{2}{*}{ Inoculum level } & \multicolumn{2}{c}{ Cultivar } \\
\cline { 2 - 3 } & Mirage & Long Green \\
\hline 250 & $3.4 \pm 0.42$ & $0.2 \pm 0.10$ \\
\hline 500 & $5.3 \pm 0.97$ & $0.9 \pm 0.22$ \\
\hline 1000 & $6.7 \pm 1.13$ & $1.2 \pm 0.35$ \\
\hline 2000 & $17.2 \pm 1.35$ & $3.3 \pm 0.53$ \\
\hline 4000 & $24.0 \pm 1.73$ & $5.4 \pm 0.54$ \\
\hline 8000 & $26.3 \pm 1.87$ & $6.7 \pm 0.77$ \\
\hline
\end{tabular}

Data are means of ten replicates.

Table 7. Effect of inoculum levels of Meloidogyne incognita on \% decrease in fruit weight of resistant and highly susceptible cucumber cultivars.

\begin{tabular}{|c|c|c|}
\hline \multirow{2}{*}{ Inoculum level } & \multicolumn{2}{|c|}{ Cultivar } \\
\hline & Mirage & Long Green \\
\hline 250 & $2.1 \pm 0.31$ & $0.1 \pm 0.05$ \\
\hline 500 & $5.4 \pm 0.67$ & $1.2 \pm 0.32$ \\
\hline 1000 & $7.8 \pm 1.24$ & $2.0 \pm 0.54$ \\
\hline 2000 & $15.2 \pm 1.32$ & $2.1 \pm 0.57$ \\
\hline 4000 & $19.4 \pm 1.33$ & $4.5 \pm 0.53$ \\
\hline 8000 & $29.6 \pm 1.87$ & $8.0 \pm 0.87$ \\
\hline
\end{tabular}

Data are means of ten replicates. 
Table 8. Effect of inoculum levels of Meloidogyne incognita on \% decrease in fruit yield of resistant and highly susceptible cucumber cultivars.

\begin{tabular}{ccc}
\hline \multirow{2}{*}{ Inoculum level } & \multicolumn{2}{c}{ Cultivar } \\
\cline { 2 - 3 } & Mirage & Long Green \\
\hline 250 & $3.7 \pm 0.43$ & $0.7 \pm 0.13$ \\
\hline 500 & $5.2 \pm 0.67$ & $1.1 \pm 0.32$ \\
\hline 1000 & $11.3 \pm 1.32$ & $3.4 \pm 0.45$ \\
\hline 2000 & $13.9 \pm 1.43$ & $6.3 \pm 0.66$ \\
\hline 4000 & $24.8 \pm 1.93$ & $7.9 \pm 0.75$ \\
\hline 8000 & $40.6 \pm 2.23$ & $11.4 \pm 1.24$ \\
\hline
\end{tabular}

Data are means of ten replicates.

\section{Nematode infestations on resistant and susceptible cucumber cultivars}

Significant differences in number of galls and egg masses were noticed between the resistant and highly susceptible cultivars at all inoculum levels. The nematode produced the maximum galls on the roots of resistant and highly susceptible cultivars at a level of $8000 \mathrm{~J} 2 \mathrm{~s}$ followed by 4000 and $2000 \mathrm{~J} 2 \mathrm{~s}$ inoculum levels. On the contrary, the minimum galls and egg masses were observed at the lowest inoculum level of $250 \mathrm{~J} 2 \mathrm{~s}$ followed by the densities of 500 and $1000 \mathrm{~J} 2 \mathrm{~s}$ (Figs. 1 and 2). The galls produced on the highly susceptible cultivar were significantly higher as compared to the resistant one. Again, direct relationships were observed between inoculum levels and number of galls and egg masses as represented by regression equations and trend lines in Figs. 1 and 2.

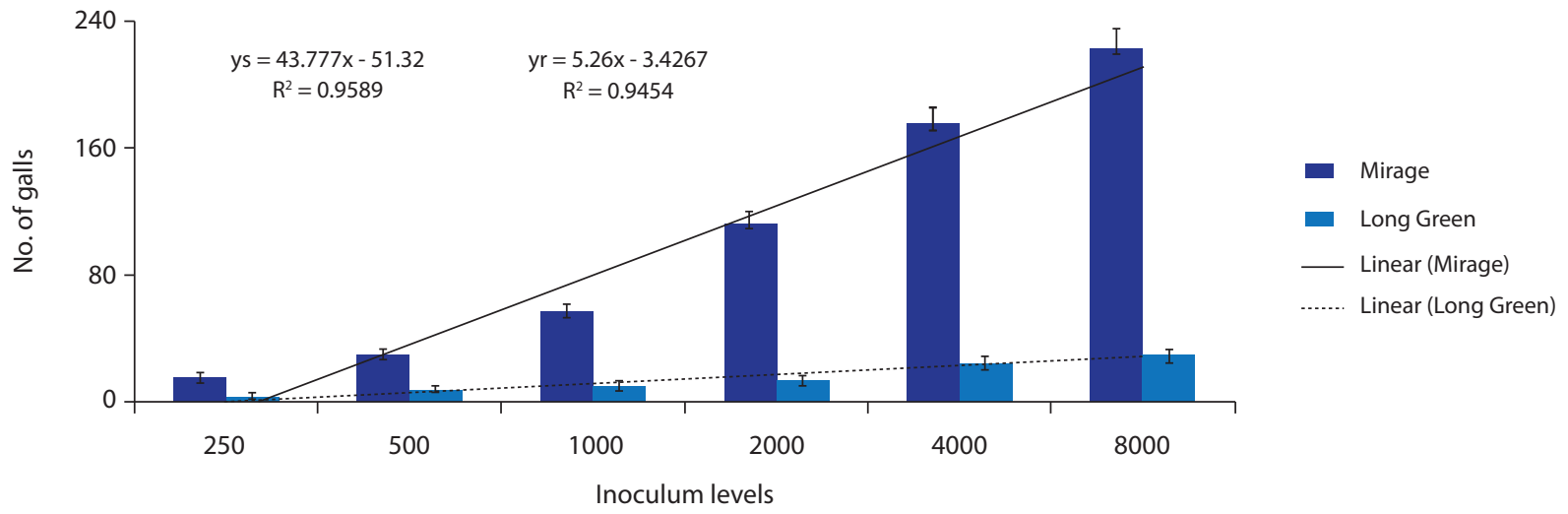

Figure 1. Number of galls on resistant and highly susceptible cucumber cultivars.

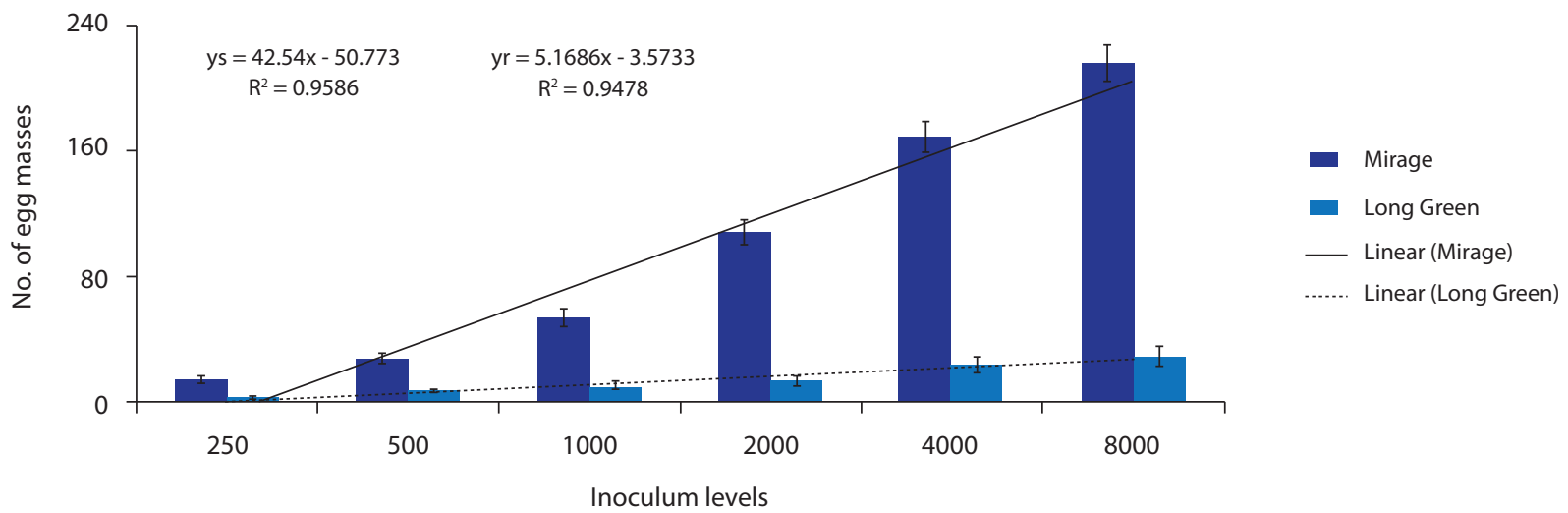

Figure 2. Number of egg masses on resistant and highly susceptible cucumber cultivars. 
On the other hand, all the inoculum levels significantly varied regarding reproductive factor on the resistant and the highly susceptible cultivars. The maximum reproductive factor of 16.96-fold was observed at the lowest inoculum level in the highly susceptible cultivar while in the resistant cultivar the maximum reproductive factor of 3.72 -fold was found at the same inoculum level. On the other hand, the highest inoculum level of $8000 \mathrm{~J} 2 \mathrm{~s}$ gave the minimum reproductive factors of 0.96 and 8.23-folds in the resistant and the highly susceptible cultivars as shown in Fig. 3. It was found that there was a corresponding decrease in the reproductive factor for both cultivars with an increase in the level of inoculum, showing inverse relationships, which can be seen by regression equations and trend lines in Fig. 3.

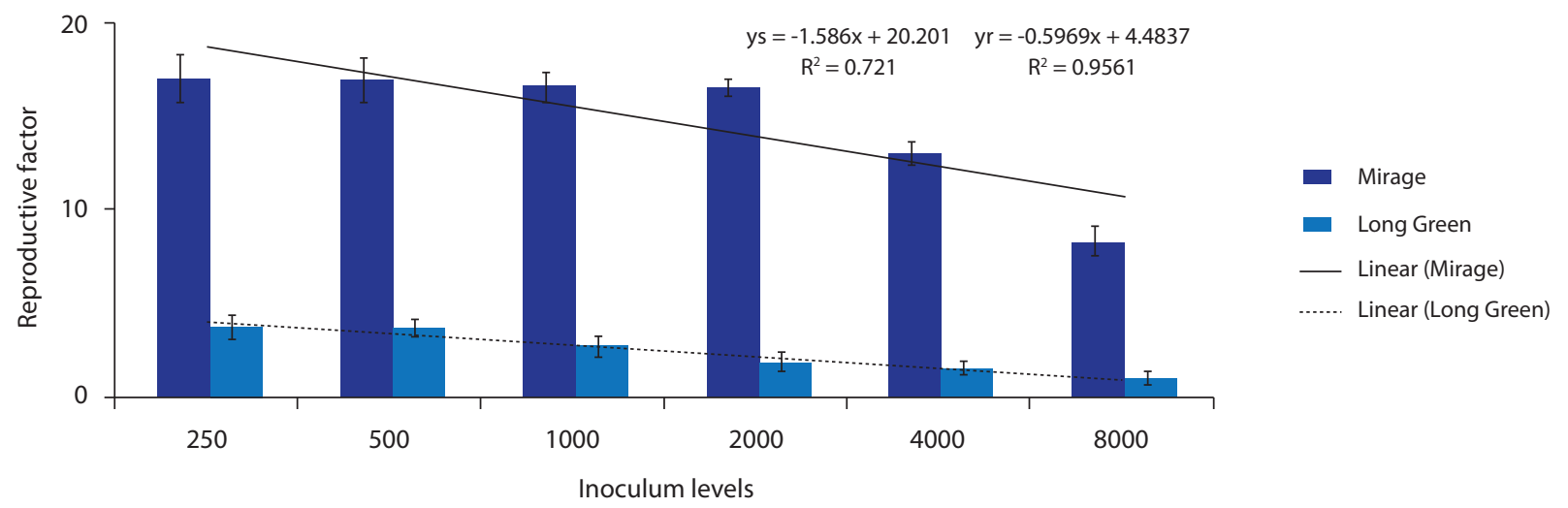

Figure 3. Reproductive factor of Meloidogyne incognita on resistant and highly susceptible cucumber cultivars.

\section{DISCUSSION}

In the present study, the effects of six inoculum levels of $M$. incognita were compared on a highly susceptible cultivar (Mirage) and a resistant one (Long Green) of cucumber. All the inoculum densities of $M$. incognita resulted in significant reductions in growth and yield variables and increases in nematode infestations of both cultivars over their controls. The reductions in the resistant cultivar were significantly lower when compared to the highly susceptible one at all inoculum levels.

The maximum reductions in growth and yield variables in the highly susceptible cultivar can be imputed to severe root damage due to penetration and/or feeding of maximum numbers of nematodes into the roots, which resulted in impairment and disruption of water absorption by the infected root systems. After penetration into roots, the root-knot females induced gall formation and giant cells in the stellar region and caused severe disruption of xylem tissues. Due to extensive disruption of xylem vessels, the upward uptake of water and nutrients was greatly reduced. The root-knot infection also greatly affected permeability of roots to water. Due to induction of nurse cell systems by the females of rootknot nematodes for incessant feeding in infected roots, there was a greater translocation of photosynthates towards these infection sites while the above ground parts experienced acute deficiency of nutrients (Wyss 2002; Di Vito et al. 2004). As the infected plants faced insufficient supply of nutrients, photosynthates, energy, water etc., therefore, the development and growth of leaf tissues and their essential constituents, particularly chlorophyll pigments, were greatly hampered (Khan and Khan 1997). The stunted and reduced growth of foliar parts subsequently results in reduced biomass and productivity (Khan et al. 2019). On the other hand, minimum numbers of nematodes entered into the roots of the resistant cultivar resulting in less root damage, reduced and/or poor induction of galls and giant cells causing no significant foliar damage. This resulted in insignificant foliar damage and growth and yield variables were least affected causing minimum reductions in these parameters on the resistant cultivar.

The successful parasitism by root-knot nematodes in vascular tissues of highly susceptible plants is characterized by the formation of giant cells. These nurse cells are highly specific and are induced and maintained by females of root-knot nematodes. On the other hand, in the resistant cultivar, the juveniles cannot induce the development of giant cells essential 
for successful parasitism and, consequently, the juveniles either die or leave the roots. As a result of unsuccessful parasitism, there is no infection of the host and the yield is not affected. The other major factors that determine the variations in growth and yield variables among cucumber cultivars are the multiplication of nematodes in the hosts and production of egg masses on the roots by females (Mukhtar and Hussain 2019). The variations in reproductive rates might partially be the result of genetic factors which impart resistance or susceptibility to the host or due to genetic variations in nematode populations (Griffin 1982; Jacquet et al. 2005; Castagnone-Sereno 2006). The variations in the hosts can influence various stages in the life cycle of the nematode. The juveniles either fail to enter the resistant hosts or they are killed after their penetration into the roots. If somehow the juveniles are successful in entering the roots of resistant cultivars, there will be no development and/or reproduction of the nematode.

The variations in reproduction and multiplication of $M$. incognita on cucumber cultivars are owing to variations in their genetic makeup which can be explained in terms of number of egg masses (Mukhtar et al. 2013). The production of maximum egg masses and eggs on the roots in the highly susceptible cultivar explains that maximum numbers of juveniles entered the roots and were successful in completing their life cycles in the host. On the contrary, only few juveniles made their way into the roots of resistant cultivar and got matured, which is obvious by the number of egg masses and their reproductive factors (Khan et al. 2019). Resistant cultivars contain a limited number of developed nematodes as compared to susceptible cultivars (Dropkin and Nelson 1960). The hindrance in invasion by second-stage juveniles of the nematode has been ascribed to failure to develop the maximum number of juveniles in the infected roots and/or hypersensitive reactions in the host (Dropkin 1969). In the case of susceptible hosts, the juveniles had the maximum potential to fully develop, as evident by their reproductive factors in the highly susceptible cultivar (Mukhtar and Hussain 2019). On the other hand, in the resistant cultivar, the development of the juveniles was either curtailed or delayed (Nelson et al. 1990).

High rate of multiplication of nematodes with low level of inocula might be due to encouraging factors like plenty of food, reduced competition level and the ability of hosts to support these populations (Haynes and Jones 1976; Bendezu and Starr 2003). Initial densities of $M$. javanica affected the rate of nematode multiplication; higher reproduction rates were observed where initial densities were lower. This might be due to destruction of root system by the nematodes. As rootknot nematodes are more pathogenic and damaging at higher densities, the larvae of subsequent generations fail to locate new infectious sites (Ogunfowora 1977). According to Oostenbrink (1966), initial density of nematodes is responsible for subsequent reduction in yield of crops and increase in nematode populations. In the present study, final nematode populations and gall formations proportionally affected plant growth variables which corroborated the findings of Oostenbrink (1966).

\section{CONCLUSION}

In the present study, significant differences in growth reductions and increase in nematode infections were observed in the resistant and the highly susceptible cucumber cultivars at all inoculum levels. The plants of resistant cultivar Long Green suffered less damage and suppressed nematode infection at all inoculum levels and are, therefore, recommended for cultivation in root-knot nematode infested fields to abate yield losses and repress the nematode from further multiplication.

\section{REFERENCES}

Archana, B. and Saxena, R. (2012). Nematicidal effect of root extract of certain medicinal plants in control of Meloidogyne incognita in vitro and in vivo conditions. Pakistan Journal of Nematology, 30, 179-187.

Asghar, A., Mukhtar, T., Raja, M. U. and Gulzar, A. (2020). Interaction between Meloidogyne javanica and Ralstonia solanacearum in chili. Pakistan Journal of Zoology, 52, https://doi.org/10.17582/journal.pjz/2020.52 
Aslam, M. A., Javed, K., Javed, H., Mukhtar, T. and Bashir, M. S. (2019 a). Infestation of Helicoverpa armigera Hübner (Noctuidae: Lepidoptera) on soybean cultivars in Pothwar region and relationship with physico-morphic characters. Pakistan Journal of Agricultural Sciences, 56, 401-405. https://doi.org/10.21162/PAKJAS/19.6979

Aslam, M. N., Mukhtar, T., Jamil, M. and Nafees, M. (2019 b). Analysis of aubergine germplasm for resistance sources to bacterial wilt incited by Ralstonia solanacearum. Pakistan Journal of Agricultural Sciences, 56, 119-122.

Azeem, W., Mukhtar, T. and Hamid, T. (2020). Evaluation of Trichoderma harzianum and Azadirachta indica in the management of Meloidogyne incognita in Tomato. Pakistan Journal of Zoology, 52. https://doi.org/10.17582/journal.pjz/2020.52

Barker, K. R. and Olthof, T. H. A. (1976). Relationship between nematode population densities and crop responses. Annual Review of Phytopathology, 14, 327-353. https://doi.org/10.1146/annurev.py.14.090176.001551

Bendezu, I. F. and Starr, J. (2003). Mechanism of resistance to Meloidogyne arenaria in the peanut cultivar COAN. Journal of Nematology, $35,115-118$.

Castagnone-Sereno, P. (2006). Genetic variability and adaptive evolution in parthenogenetic root-knot nematodes. Heredity, 96, 282289. https://doi.org/10.1038/sj.hdy.6800794

Di Vito, M., Vovlas, N. and Castillo, P. (2004). Host-parasite relationships of Meloidogyne incognita on spinach. Plant Pathology, 53, 508514. https://doi.org/10.1046/j.0032-0862.2004.01053.x

Dropkin, V. H. and Nelson, P. E. (1960). The histopathology of root-knot nematode infection in soybeans. Phytopathology, $50,442-447$.

Dropkin, V. H. (1969). The necrotic reaction of tomatoes and other hosts resistant to Meloidogyne: reversal by temperature. Phytopathology, 59, 1632-1637.

Elling, A. A. (2013). Major emerging problems with minor Meloidogyne species. Phytopathology, 103, 1092-1102. https://doi.org/10.1094/ PHYTO-01-13-0019-RVW

Griffin, G. D. (1982). Concomitant relationships of Meloidogyne hapla and Heterodera schachtii on tomato. Journal of Nematology, 14, 444-445.

Haynes, R. L. and Jones, C. M. (1976). Effect of the Bi locus in cucumber on reproduction, attraction and response of plant to infection by the root-knot nematode. Journal of American Society of Horticultural Sciences, 101, 422-424.

Hussain, M. A. and Mukhtar, T. (2019). Root-knot nematodes infecting okra in major vegetable growing districts of Punjab, Pakistan. Pakistan Journal of Zoology, 51, 1137-1143. https://doi.org/10.17582/journal.pjz/2019.51.3.1137.1143

Hussey, R. S. and Barker, K. R. (1973). A comparison of methods of collecting inocula of Meloidogyne spp. including a new technique. Plant Disease Reporter, 57, 1025-1028.

Iqbal, U. and Mukhtar, T. (2020). Inhibitory effects of some fungicides against Macrophomina phaseolina causing charcoal rot. Pakistan Journal of Zoology, 52, 709-715. https://doi.org/10.17582/journal.pjz/20181228101230

Jacquet, M., Bongiovanni, M., Martinez, M., Verschave, P., Wajnberg, E. and Castagnone-Sereno, P. (2005). Variation in resistance to the root-knot nematode Meloidogyne incognita in tomato genotypes bearing the Mi gene. Plant Pathology, 54, 93-99. https://doi. org/10.1111/j.1365-3059.2005.01143.x

Javed, K., Javed, H., Mukhtar, T. and Qiu, D. (2019 a). Efficacy of Beauveria bassiana and Verticillium lecanii for the management of whitefly and aphid. Pakistan Journal of Agricultural Sciences, 56, 669-674. https://doi.org/10.21162/PAKJAS/19.8396

Javed, K., Javed, H., Mukhtar, T. and Qiu, D. (2019 b). Pathogenicity of some entomopathogenic fungal strains to green peach aphid, Myzus persicae Sulzer (Homoptera: Aphididae). Egyptian Journal of Biological Pest Control, 29, 92, https://doi.org/10.1186/s41938-019-0183-z 
Kassi, A. K., Javed, H. and Mukhtar, T. (2019 a). Relationship of physico-morphic characters of okra cultivars with their resistance to Helicoverpa armigera. Pakistan Journal of Zoology, 51, 835-841. https://doi.org/10.17582/journal.pjz/2019.51.3.835.841

Kassi, A. K., Javed, H. and Mukhtar, T. (2019 b). Screening of different aubergine cultivars against infestation of brinjal fruit and shoot borer (Leucinodes orbonalis Guenee). Pakistan Journal of Zoology, 51, 603-609. https://doi.org/10.17582/journal.pjz/2019.51.2.603.609

Kayani, M. Z., Mukhtar, T. and Hussain, M. A. (2018). Interaction between nematode inoculum density and plant age on growth and yield of cucumber and reproduction of Meloidogyne incognita. Pakistan Journal of Zoology, 50, 3, 897-902. https://doi.org/10.17582/ journal.pjz/2018.50.3.897.902

Kayani, M. Z., Mukhtar, T., Hussain, M. A. and UI-Haque, M. I. (2013). Infestation assessment of root-knot nematodes (Meloidogyne spp.) associated with cucumber in the Pothowar region of Pakistan. Crop Protection, 47, 49-54. https://doi.org/10.1016/j.cropro.2013.01.005

Khan, M. R. and Khan, M. W. (1997). Effects of root-knot nematode, Meloidogyne incognita, on the sensitivity of tomato to sulphur dioxide and ozone. Environmental and Experimental Botany, 38, 117-130. https://doi.org/10.1016/S0098-8472(96)01060-X

Khan, M. T. A., Mukhtar, T. and Saeed, M. (2019). Resistance or susceptibility of eight aubergine cultivars to Meloidogyne javanica. Pakistan Journal of Zoology, 51, 2187-2192.

Madamba, C. P., Sasser, J. N. and Nelson, L. A. (1965). Some characteristics of the effects of Meloidogyne spp. on unstable host crops. North Carolina Agricultural Experiment Station Technical Bulletin, 169, 1-34.

Mukhtar, T. and Hussain, M. A. (2019). Pathogenic potential of Javanese root-knot nematode on susceptible and resistant okra cultivars. Pakistan Journal of Zoology, 51, 5, 1891-1897. https://doi.org/10.17582/journal.pjz/2019.51.5.1891.1897

Mukhtar, T. and Kayani, M. Z. (2019). Growth and yield responses of fifteen cucumber cultivars to root-knot nematode (Meloidogyne incognita). Acta Scientiarum Polonorum Hortorum Cultus, 18, 3, 45-52. https://doi.org/10.24326/asphc.2019.3.5

Mukhtar, T., Kayani, M. Z. and Hussain, M. A. (2013). Response of selected cucumber cultivars to Meloidogyne incognita. Crop Protection, 44, 13-17. https://doi.org/10.1016/j.cropro.2012.10.015

Nazir, K., Mukhtar, T. and Javed, H. (2019). In vitro effectiveness of silver nanoparticles against root-knot nematode (Meloidogyne incognita). Pakistan Journal of Zoology, 51, 2077-2083. https://doi.org/10.17582/journal.pjz/2019.51.6.2077.2083

Nelson, S. C., Starr, J. L. and Simpson, C. E. (1990). Expression of resistance to Meloidogyne arenaria in Arachis batizocoi and A. cardenasii. Journal of Nematology, 22, 423-425.

Ogunfowora, A. O. (1977). The effects of different population levels of Meloidogyne incognita on yield of tomato (Lycopersicon esculentum) in Southern Western Nigeria. Nigerian Journal of Plant Protection, 3, 61-67.

Olthof, T. H. A. and Potter, J. W. (1972). Relationship between population densities of Meloidogyne hapla and crop losses in summer maturing vegetables in Ontario. Phytopathology, 62, 981-986. https://doi.org/10.1094/Phyto-62-981

Oostenbrink, M. (1966). Major characteristics of the relationships between nematodes and plants. Meded Land Gesch Wageningen, $66,1-46$.

Rahoo, A. M., Mukhtar, T., Bhugio, B.A. and Rahoo, R.K. (2019 a). Comparison of infectivity and productivity of Steinernema feltiae and Heterorhabditis bacteriophora in Galleria mellonella and Tenebrio molitor. Pakistan Journal of Zoology, 51, 717-724. https://doi.org/10.17582/ journal.pjz/2019.51.2.717.724

Rahoo, A. M., Mukhtar, T., Bughio, B. A. and Rahoo, R. K. (2019 b). Relationship between the size of Galleria mellonella larvae and the production of Steinernema feltiae and Heterorhabditis bacteriophora. Pakistan Journal of Zoology, 51, 79-84. https://doi.org/10.17582/ journal.pjz/2019.51 
Saeed, M., Mukhtar, T. and Rehman, M. A. (2019). Temporal fluctuations in the population of citrus nematode (Tylenchulus semipenetrans) in the Pothowar region of Pakistan. Pakistan Journal of Zoology, 51, 2257-2263. https://doi.org/10.17582/journal.pjz/2019.51.6.2257.2263

Sasser, J. N. (1979). Economic importance of Meloidogyne in tropical countries. In F. Lamberti and C. E. Taylor (Eds.). Root-knot nematodes (Meloidogyne spp): Systematics, Biology and Control. (p. 359-374). New York: Acad. Press.

Sasser, J. N. and Freckman, D. W. (1987). A world prospective on nematology: the role of the society, In J.A. Veech and D.W. Dickson (Eds.), Vistas on Nematology. (p. 7-14). Hyattsville, MD: Society of Nematologists.

Tariq-Khan, M., Munir, A., Mukhtar, T., Hallmann, J. and Heuer, H. (2017). Distribution of root-knot nematode species and their virulence on vegetables in northern temperate agro-ecosystems of the Pakistani-administered territories of Azad Jammu and Kashmir. Journal of Plant Diseases and Protection, 124, 201-212. https://doi.org/10.1007/s41348-016-0045-9

Whitehead, A. G. and Hemming, J. R. (1965). A comparison of some quantitative methods of extracting small vermiform nematodes from soil. Annals of Applied Biology, 55, 25-38. https://doi.org/10.1111/j.1744-7348.1965.tb07864.x

Wyss, U. (2002). Feeding behaviour of plant parasitic nematodes, In D. L. Lee (Ed.). The biology of nematodes, (p. 233-260). London: Taylor and Francis. 